\title{
GABRIELA LEITE E MUDANÇAS NAS PRÁTICAS DISCURSIVAS SOBRE PROSTITUIÇÃO NO BRASIL*
}

Gabriela Leite and the discourse practices changes on prostitution in Brazil

Gabriela Leite y los cambios en las prácticas discursivas sobre prostitución en Brasil

APARECIDA FONSECA MORAES ${ }^{\text {I** }}$

DOI: http://dx.doi.org/10.1590/S2178-14942020000200003

\footnotetext{
*Agradecimentos ao amigo André Botelho (Universidade Federal do Rio de Janeiro — UFRJ), por ter me concedido uma leitura atenta, com comentários precisos e instigantes. Agradeço também às pesquisadoras do Núcleo de Estudos de Sexualidade e Gênero (UFRJ), pelos profícuos e inspiradores debates durante a pesquisa.

Universidade Federal do Rio de Janeiro (UFRJ), Rio de Janeiro (RJ), Brasil.

**Professora associada do Departamento de Sociologia e do Programa de Pós-Graduação em Sociologia e Antropologia da UFRJ (cimoraesrj@gmail.com).

(D) https://orcid.org/0000-0002-6501-2606
}

Artigo recebido em 1 de janeiro de 2020 e aprovado para publicação em 13 de março de 2020. 


\title{
RESUMO
}

Com recortes históricos recentes, o artigo aborda as relações entre as práticas discursivas da ativista Gabriela Leite e o processo de construção das prostitutas como sujeitos políticos. Ao privilegiar perspectivas da sociologia do indivíduo, analisa a trajetória pública de Gabriela em diferentes círculos sociais (religiosos, organizações governamentais e não governamentais, entre outros) e identifica as conexões entre essa trajetória, o movimento social de prostitutas e a penetração de novas ideias e valores no campo dos direitos sexuais, destacadamente nas políticas de prevenção ao HIV/Aids. A pesquisa reuniu informações qualitativas coletadas em diferentes fontes entre os anos de 1980-1990 e, posteriormente, 2010-2013.

PALAVRAS-CHAVE: Prostituição; Gênero e sexualidade; Sociologia do indivíduo; Movimento social; HIV/Aids.

\begin{abstract}
By picking out recent historical clippings, this paper addresses the relationship between activist Gabriela Leite's discursive practices and the construction of prostitutes as political subjects. Adopting a sociology of the individual perspective, it analyzes Gabriela's public trajectory in different social circles (religious, governmental and non-governmental organizations, among others) and identifies the connections between her trajectory, the prostitutes' social movement and the diffusion of new ideas and values in the field of sexual rights, with particular emphasis on HIV/Aids prevention policies. The research gathered qualitative information collected from different sources between 1980-1990 and, later, between 2010-2013.
\end{abstract}

KEYWORDS: Prostitution; Gender and sexuality; Sociology of the individual; Social movement; HIV/Aids.

\section{RESUMEN}

En base a una selección de recortes históricos recientes, este artículo aborda las relaciones entre las prácticas discursivas de la activista Gabriela Leite y los procesos de construcción de las prostitutas en tanto sujetos políticos. Analiza la trayectoria pública de Leite en diferentes círculos sociales (religiosos, de organizaciones gubernamentales y no gubernamentales, entre otros), privilegiando las perspectivas de la sociología del individuo. Para ello identifica las conexiones entre esa trayectoria, el movimiento social de prostitutas y la penetración de nuevas ideas y valores en el campo de los derechos sexuales, dando relevancia a las políticas de prevención del VIH/Sida. La investigación reunió informaciones cualitativas recogidas a partir de diversas fuentes, entre los años 1980 y 1990 y, posteriormente, en el período 2010-2013.

PALABRAS CLAVE: Prostitución; Género y sexualidad; Sociología del individuo; Movimientos sociales; VIH/Sida. 


\section{INTRODUÇÃO}

E m 1994, sob o título "Putas políticas", Gabriela Leite comenta no jornal Beijo da rua, criado por ela, as conquistas alcançadas com mais um Encontro Nacional de Prostitutas: "somos hoje um movimento estruturado e respeitado como sério e eficaz".

Não mais frases babacas do tipo: "Gosto de ser profissional do sexo porque assim posso criar meus filhos". Ou então: "Não gosto do nome prostituta, prefiro profissional do sexo porque é mais digno". Minha angústia é a mesmice dessas frases, minha angústia é perceber o clima de chá das cinco entre putas discutindo filhos, palavras politicamente corretas, enfim, mulheres normais e santas, lutando por um lugar no céu. Renego a santidade. Sonho com a puta inteira, grandiosa e fundamental. (Leite, 1994a: 2)

Na "Coluna da Gabi", Gabriela Leite ainda ressalta o que seria o grande desafio: "[...] não deixar a racionalidade nos vencer. Não podemos perder duas grandes características lapidadas pela antiguidade da profissão: a sedução e o clima de mistério das luzes vermelhas" (Leite, 1994a: 2).

"Putas políticas" era mais do que uma expressão de impacto comunicativo. Designava uma identidade coletiva que estava sendo construída em um período histórico e contexto específico. Representações e convenções políticas, profissionais, de gênero e sexualidade, são problematizadas na citação anterior. Gabriela opõe, rejeita e interpela classificações sociais que espelham diferenciais de poder inscritos na divisão de papéis de gênero — " putas discutindo filhos", "mulheres normais e santas". Também procura ressignificar o sentido de ser profissional e pertencer a um "movimento estruturado", sem a reprodução simples de formalidades e etiquetas políticas ou profissionais - "não deixar a racionalidade nos vencer", "Sonho com a puta inteira, grandiosa e fundamental". Os relatos ilustram, afinal, como Gabriela publicizava uma representação sobre si mesma e sobre seu grupo, tecendo assim um "nós", as mulheres prostitutas.

A trajetória pessoal de Gabriela Leite é um componente relacional importante para compreendermos as condições sob as quais ocorreram mudanças nas práticas discursivas em torno do fenômeno da prostituição no Brasil contemporâneo. No fim da década de 1980, novas ideias sobre a mulher prostituta alcançaram os meios de comunicação, grupos de intelectuais e acadêmicos, artistas, representantes de círculos políticos e religiosos, de organizações governamentais, não governamentais e diferentes movimentos sociais. Esse processo também foi marcado por muitas controvérsias, inquietações ou mesmo rupturas. Iniciou-se aí um longo e tenso caminho para um reconhecimento público e político que questionava atributos negativos que associavam a mulher prostituta às ideias de passividade, isolamento, degradação, ameaça, contaminação, entre outros. 
Inciativas de associação e de organização do movimento social de prostitutas expandiram-se nos anos de 1990. No âmbito das ações, essas elaborações permitiram a constituição de articulações significativas com o Estado, influenciando políticas públicas, organizações do campo dos direitos humanos e outros movimentos sociais, percurso que não deixou de ser marcado também por tensões e ambivalências. A trajetória de Gabriela mostra, de um lado, as condições conflituosas nas quais o movimento de prostitutas se constituiu e como participou desse período da história da democratização brasileira. De outro, revela como se relacionaram as ações dessas atrizes políticas com outros atores sociais, instituições e organizações, de modo que pudessem agir aproveitando oportunidades, rejeitando rótulos e tornando inócuos os sentimentos de indulgência ou vitimização a elas dirigidos.

0 principal objetivo neste artigo é apresentar, com base em recortes históricos recentes, como estiveram imbricadas as ideias e as ações de Gabriela Leite e o processo de construção de um novo lugar social das prostitutas. Essas conexões ocorreram principalmente com o surgimento de um movimento social e pela presença dessas mulheres e suas organizações políticas em campanhas governamentais para enfrentar a epidemia da aids. Interessou-nos também identificar como, em contextos específicos, estavam associados Gabriela, outras prostitutas e indivíduos pertencentes a diferentes grupos e instituições. Por fim, analisamos a penetração e os trânsitos dessa trajetória individual em diferentes círculos sociais: círculos de representantes da Igreja Católica, de organizações não governamentais (ONGs) e grupos profissionais responsáveis por programas de prevenção à aids vinculados a ONGs ou ao Estado.

Os anos de 1980, 1990 e a primeira década dos anos 2000, demarcam o horizonte político e simbólico que compõe o cenário social multifacetado que analisamos. É importante considerar, para tanto, a penetração e a difusão de valores democráticos e normas dos direitos humanos, o que ocorreu com o trabalho de "empreendedores morais", aqui definidos como aqueles que elegem uma questão sensível ao público e lutam pela sua institucionalização em diferentes organizações (Finnemore e Sikking, 1998). Ao mesmo tempo, devem-se considerar fenômenos sociais em escala mais ampla, tais como a diversificação das lutas pelo reconhecimento de direitos sexuais e, principalmente, a articulação dessas lutas com a reorganização de movimentos homossexuais e com a manifestação de novas identidades coletivas mediante um conjunto variado de "respostas não governamentais frente à epidemia de HIVIAIDS" (Galvão, 2000: 35-105). Esses não foram elementos contextuais externos à trajetória de Gabriela e à construção de um expressivo movimento social de prostitutas no Brasil. Resguardadas as suas especificidades, podemos considerar que eles compartilhavam o mesmo léxico político e simbólico'. 
Privilegiando perspectivas da sociologia do indivíduo encontradas em Norbert Elias e recorrendo ao conceito de "círculos sociais" de George Simmel para enriquecer a análise, 0 artigo trata dos entrelaçamentos entre contextos sociais mais amplos e redes de relações individuais que Gabriela constituiu, desde a sua chegada ao Rio de Janeiro, na direção das mudanças aqui mencionadas. Para isso, privilegiamos recortar os acontecimentos presentes na trajetória de Gabriela no Rio de Janeiro tomando como base a ampliação de suas redes sociais e a intensificação de diálogos, conflitos, disputas discursivas e interpretativas. Na seção "Grupos religiosos, organização não governamental e associação de prostitutas", na qual se segue a uma breve apresentação de Gabriela Leite, abordamos a sua relação com grupos da Igreja Católica que praticavam militância ou filantropia em instituições religiosas, a associação com o movimento de prostitutas e a construção de novas redes de relações com a sua entrada em uma ONG. O segundo contexto analisado, "Não governamental, governamental e as lutas contra aids", entrelaça dois eventos: a criação de uma ONG, a Davida, e a ampliação da participação de Gabriela em políticas e campanhas de prevenção à aids por meio dessa organização, o que também a aproxima de outros grupos de ativistas e profissionais de várias ONGs e do Estado. A seção "'Putas políticas' e a grife de moda Daspu" examina o que chamamos de um novo giro performativo de Gabriela. Nessa seção, mostramos conexões entre mudanças no contexto das políticas governamentais de prevenção à aids e as novas respostas e ações críticas e criativas de Gabriela, como a criação da grife Daspu e o lançamento de sua candidatura à Câmara Federal com o slogan "Puta deputada".

\section{GABRIELA, SUAS REDES E CÍRCULOS SOCIAIS: ARTICULAÇÕES COM A SOCIOLOGIA DO INDIVÍDUO}

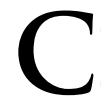
onsiderando a amplitude teórica do tema indivíduo e sociedade na sociologia, é evidente que o propósito desta seção está delimitado à apresentação de alguns pressupostos que orientaram nossa análise. Este artigo tangencia contribuições do pensamento de Norbert Elias direcionando-se, primeiramente, pelo estudo sobre a vida do músico Mozart, nascido na Áustria. Elias demonstra a importância de conhecermos a sociedade e as relações sociais em um período sócio-histórico específico para a compreensão da singularidade de um indivíduo. Ainda que se possa dizer que esse estudo destina um peso considerável às estruturas de controle social, Elias também recorre à vida de Mozart para mostrar como os limites da sociedade são experimentados conflituosamente diante das oportunidades que, mesmo não sendo criadas pelo indivíduo (Elias, 1995: 29), podem gerar diferentes respostas. Tal singularidade individual, em certa medida, contribui para o desenvolvimento e o conhecimento de si: 
[...] Só então, em suma, é possível entender as coerções inevitáveis que agiam sobre Mozart e como ele se comportou em relação a elas — se cedeu à sua pressão e foi assim influenciado em sua produção musical, ou se tentou escapar ou mesmo se opor a elas. (Elias, 1995: 19)

Porém, a ideia de que a rede de relações sociais e pessoais funciona ao mesmo tempo para a modelagem individual e o desenvolvimento da individualidade pode ser problematizada quando Elias destaca os avanços do "processo civilizador". Quanto mais os indivíduos se associam em redes diferenciadas, maior o controle das pulsões, das emoções e dos instintos, o que ocorreria mediante mudanças na própria estrutura da sociedade e da personalidade afetando, portanto, o comportamento individual, uma vez que as exigências sociais seriam crescentemente interiorizadas (Elias, 1993).

Essa perspectiva levou à necessidade de alargarmos as contribuições de Elias lançando mão do conceito de círculos sociais de George Simmel. Na sociologia dos círculos sociais (Simmel, 2009), tanto mais o indivíduo encontra-se entrecruzado por numerosos círculos, tanto mais rica é a sua participação na vida social e mais forte pode se tornar a expressão da sua individualidade (Filho, 1983: 15 e 23-24). Afinal, como ampliar a compreensão sobre a maneira como Gabriela, inserida em uma modernidade com avançado processo de diferenciação social, pôde expressar a sua autonomia, criatividade e liberdade ao encarnar a identidade de mulher "puta" ? Como ela aproveitou as oportunidades oferecidas nas suas diferentes redes sociais? Como a mulher que proclamava uma identidade de gênero dissidente e contrastiva em relação aos grupos "estabelecidos" foi diferenciando-se à medida que transitava por esses círculos e mantinha-se socialmente integrada? Segundo Levine (2015: 42), Simmel destacou que a tendência da "ordem moderna" é "diferenciar e promover características opostas" e, quanto ao desenvolvimento da individualidade, o autor " [...] vê a ordem social e cultural modernas como liberação de forças que a um só tempo aumentam e ameaçam as possibilidades de individualidade genuína" (Levine, 2015: 42). A perspectiva simmeliana sobre o crescimento dos círculos sociais na modernidade também se situa nessa chave de dupla possibilidade interpretativa. Por essa perspectiva, podemos dizer que o crescimento dos círculos sociais seria o principal fator responsável pela existência de conflitos, mas a ampliação da inserção do indivíduo em diferentes círculos também possibilitaria a construção de indivíduos com mais autonomia, liberdade e diferenciação recíproca (Alves e Maciel, 2017: 271-272).

À medida que alcançava reconhecimento, Gabriela circulava em grupos estabelecidos diversos, tornando-se cada vez mais integrada, mas também mais livre e autônoma em relação a eles. Ao lado de suas "colegas" e de outros grupos ativistas, Gabriela fortaleceu a identidade política da categoria ao associar-se e transitar em diferentes círculos 
sociais, contribuindo também para a abertura de criativos caminhos para o nascimento e o reconhecimento de organizações de prostitutas no Brasil. Analisar o alargamento de sua experiência individual ajuda a entender seus principais desafios, tensões e conflitos, mas também fenômenos sociais relacionados com a emergência e as conquistas de associações e movimentos sociais de prostitutas. Conforme desenvolvemos mais adiante, a imbricação da trajetória pessoal de Gabriela com o processo mais amplo de fortalecimento de atores políticos, especificamente por meio de organizações da sociedade civil, e a vinculação com as políticas de prevenção à aids contribuíram para ampliar as oportunidades de desenvolvimento do projeto de construção de si.

Evidentemente, esse percurso não foi linear. Em momentos e intensidades diferentes, acentuaram-se as tensões entre as posições outsider-establishment, definições utilizadas por Elias e Scotson (2000) para referirem-se às relações entre grupos "observantes" e "não observantes" de normas e restrições de uma coletividade ${ }^{2}$. A referência aqui contribui para descrever e analisar, ao longo de outras seções do artigo, a maneira como Gabriela desafiava as restrições ou mesmo as normas, o que sublinhava a sua posição ou identidade outsider em grupos e instituições nos quais circulou. Ao mesmo tempo em que as interações apareciam mais marcadas por tensões, tornando instável a sua presença em determinados círculos sociais, havia também alguma ambivalência, uma vez que algum tipo de "atração" frequentemente se expressava ${ }^{3}$. Nesse sentido, procuramos apreender na análise a dimensão dos conflitos e tensões que os indivíduos experimentam na intersecção de diferentes círculos sociais, o que, na trajetória de Gabriela, se expressou como um dilema muito presente: tornar-se cada vez mais "estabelecida" na sociedade, entre instituições e grupos ativistas e, paradoxalmente, ser identificada ou sentir-se como outsider.

\section{CAMINHOS DA PESQUISA}

1 pesquisa para a elaboração deste artigo implicou em reunir informações coletadas,
arquivadas e sistematizadas pela autora entre os anos de 1980 e 1990 e, posteriormente, entre 2010 e 2013. Além de entrevistas abertas realizadas com Gabriela Leite e, individualmente, com outras prostitutas ativistas, foram analisadas anotações etnográficas de encontros, reuniões e outros diferentes eventos que congregaram prostitutas no Rio de Janeiro e em outros estados. Um diversificado material arquivado também foi explorado: entrevistas, artigos e registros biográficos de autoria de Gabriela Leite publicados em revistas, livros, jornais, especialmente as publicações do jornal Beijo da rua 4 . Filmes, documentários, além de programas de rádio e TV com a participação de Gabriela também foram reunidos e consultados. Serviram como informação complementar anotações de uma pesquisa ainda em 
curso que reúnem conversas informais e entrevistas realizadas com pessoas que conviveram com Gabriela em diferentes instituições.

A organização e a análise do material estiveram orientadas para identificar e selecionar momentos da trajetória pessoal de Gabriela nos quais estaria mais marcada a sua entrada em diferentes círculos sociais e mais explicitadas as tensões nos cruzamentos desses círculos e interações. É importante lembrar que trajetórias individuais não obedecem a cursos sequenciais coerentes e lineares. Conforme sublinha Montagner (2007: 251), ao discutir o conceito de biografia em Pierre Bourdieu, " [...] esta é uma construção realizada a posteriori pelo indivíduo ou pelo pesquisador no momento em que produz um relato oral, uma narrativa". Compreendida dessa forma, a seleção e a organização dos eventos em torno de Gabriela procuraram alinhar e interpretar as conexões entre essa trajetória individual e as condições, práticas e discursivas, nas quais iam ocorrendo a sua entrada e associação em redes sociais mais amplas.

\section{"GABRIELA"}

o início dos anos de 1970, período da ditadura militar, Gabriela Leite cursava ciências
sociais na Universidade de São Paulo (USP) e frequentava redutos boêmios nos quais se relacionava com intelectuais e artistas da esquerda brasileira. Gabriela nasceu na cidade de São Paulo em 1951, no dia 22 de abril, filha de uma costureira e um crupiế. A decisão de tornar-se prostituta foi movida por uma "curiosidade e pelo desejo de uma revolução pessoal"6. Foi na Boca do Lixo, conhecida como uma "zona de baixo meretrício", que Gabriela Leite teve a sua primeira experiência. Em 1981, denunciou arbitrariedades e a violência policial contra prostitutas (Pheterson, 1989: 288) e, em junho de 1983, destacou-se na passeata de prostitutas e homossexuais "contra o terror exercido pelo então delegado Richetti" (Mulherio, 1987).

Em fevereiro de 1982, Gabriela chega ao Rio de Janeiro e faz uma breve passagem por Copacabana, quando viveu a experiência de ser "barrada" por ser uma mulher "branca" que tentava entrar em uma boate de programas sexuais cujos clientes tinham "preferência por mulheres negras e mulatas". Não demorou muito para que ela procurasse a "famosíssima Zona do Mangue", já então renomeada "Vila Mimosa: zona de que gosto, com homens trabalhadores, operários, camelôs, taxistas, caminhoneiros, enfim, homens brasileiros de todas as regiões do país que lutam para sobreviver" (Leite, 2009: 102-103). Este então se tornará, de maneira crescente, o seu espaço de trabalho, sociabilidade, diversão e ativismo.

Ao chegar à Vila Mimosa, Gabriela já conhecia diversas obras literárias. Leitora de Machado de Assis, Jorge Amado, escritor que Ihe inspirou o nome "Gabriela", entre outros, 
suas primeiras entrevistas demonstravam seu conhecimento da literatura brasileira ${ }^{7}$. Seus discursos cativantes, perspicazes, como também provocantes ou irreverentes ao interpelar o senso comum, causavam forte impacto na opinião pública. É a partir desse período que Gabriela alcança visibilidade como uma prostituta que reivindica direitos e reconhecimento social e político para a sua categoria.

Pouco a pouco, Gabriela organizou uma Rede Nacional de Prostitutas e vários encontros nacionais e regionais no Brasil, com a participação de outras lideranças, como Lourdes Barreto, de Belém do Pará. Além disso, marcava presença nos meios de comunicação e em inúmeros encontros, congressos e seminários de âmbito nacional e internacional. Nesses espaços, discutia sobre o movimento de prostitutas, relações do Estado com o terceiro setor, além de questões específicas, tais como violência policial, doenças sexualmente transmissíveis e aids e a regulamentação do trabalho sexual. Pouco antes de passar um ano lutando contra um câncer que tiraria a sua vida em 2013, Gabriela lançou no Rio de Janeiro sua candidatura a uma vaga na Câmara Federal.

A valorização da prostituição como uma profissão foi uma chave discursiva importante na gramática política desenvolvida por Gabriela. Ela retratava mulheres prostitutas, e a si mesma, como "profissionais", "especialistas em fantasias sexuais". A valorização do trabalho da prostituta e a possibilidade de este ser pensado como uma escolha ou uma alternativa diante de situações consideradas exploradoras embasaram argumentos em torno do "orgulho" de ser prostituta.

[...] mas se temos a consciência de que somos especialistas em fantasias sexuais, que não vendemos e nem alugamos nosso corpo e sim vendemos fantasias sexuais a homens ávidos dessas fantasias, então seremos mais felizes e poderemos viver nossa profissão com mais tranquilidade e até com orgulho. Eu tenho orgulho de ter exercido por tantos anos essa profissão. Tenho orguIho de conhecer homens e suas fantasias, tenho orgulho de ter dado felicidade a esses homens quando consegui entender suas fantasias. (Leite, 2002: 16)

As transições institucionais experimentadas por Gabriela Leite - da proximidade com grupos que praticavam a filantropia católica para o chamado mundo das ONGs e, posteriormente, as parcerias com o Estado e organizações que participavam de campanhas de prevenção à aids - foram marcadas por sua presença crítica e questionadora. Gabriela circulou em grupos acadêmicos e intelectuais, muitos deles vinculados à chamada "esquerda brasileira", além de outros círculos profissionais. Em um Brasil que se encontrava em período preambular de democratização, Gabriela publicizou a sua identidade de mulher na prostituição e apresentava-se como aquela que escolhera ser prostituta. 


\section{GRUPOS RELIGIOSOS, ORGANIZAÇÃO NÃO GOVERNAMENTAL E ASSOCIAÇÃO DE PROSTITUTAS}

E importante situar aqui as passagens de Gabriela em organizações sociais vinculadas à Igreja Católica, especificamente na Arquidiocese do Rio de Janeiro. É o caso do Banco da Providência, organização que desenvolve projetos de capacitação profissional e geração de renda, e da Pastoral da Mulher Marginalizada (PMM), cuja principal atuação evangelizadora se dá com a mulher prostituta ${ }^{8}$. Posteriormente destacaremos momentos do ativismo de Gabriela na primeira associação de prostitutas criada no Rio de Janeiro e o período de quase seis anos no qual trabalhou no Instituto de Estudos da Religião (ISER), uma ONG que reunia intelectuais, acadêmicos, interlocutores da esquerda brasileira e defensores dos direitos humanos.

O livro Filha, mãe, avó e puta, autoria de Gabriela Leite em depoimento a Marcia Zanellato, oferece uma detalhada descrição de seus contatos com grupos religiosos quando já trabaIhava como prostituta na Vila Mimosa. Gabriela já havia se aproximado das crianças que ficavam brincando nos arredores da zona de prostituição, "muitas filhas de prostitutas moradoras de um prédio abandonado perto da Vila", quando recebeu o convite para desenvolver atividades pedagógicas em um projeto social no posto de atendimento do Banco da Providência (Leite, 2009: 138-139). A participação de Gabriela na PMM é lembrada como um encontro conflitivo com mulheres católicas do Banco da Providência que insistiam em ensinar às prostitutas " [...] a pintar florzinha em pote de maionese Hellmann's e colocar babado naquela tampa laranja. E diziam que aquilo era uma alternativa de renda para puta!" (Leite, 2009: 139). Naquele momento, a presença de uma mulher que recusava o rótulo de vítima e se apresentava como prostituta também já era vista como um "mau exemplo para as crianças", tensão que culminou com sua apresentação pública em um encontro da pastoral ocorrido em Salvador:

A colega mineira falou antes de mim e se apresentou assim: "Boa noite, meu nome é Suely e eu sou uma 'menina' de Uberaba". Menina? [...] Até hoje eles usam essa terminologia. Aí chegou a minha vez de falar: "Meu nome é Gabriela e, ao contrário da minha colega de Uberaba, eu sou uma prostituta e vivo no Rio de Janeiro". (Leite, 2009: 142)

Conforme argumentou Skackauskas (2017: 92-93), o trabalho da PMM pode ser visto por muitas prostitutas como uma "oportunidade para expressar suas ideias e sentimentos", ou mesmo para "questionar, confrontar, desafiar a figura do sujeito benevolente". Porém, tais reações também poderiam ser transformadas pelos próprios agentes da pastoral diante de outras estratégias caracterizadas pela autora como uma "violência simbólica contra essas mulheres".

As relações de Gabriela com a PMM e o Banco da Providência foram marcadas principlamente por rupturas discursivas. Muitas vezes ela expressou as contradições e as divergên- 
cias entre os dois projetos: a mulher que se apresentava como prostituta e a vítima "marginalizada" que a Igreja Católica queria salvar. 0 afastamento do Banco da Providência aconteceu com críticas à visão institucional dominante que "defende o fim da prostituição e acredita que a prostituta é uma vítima da sociedade machista" (Leite, 2009: 141). Ao contrário da instituição católica, Gabriela projetava mulheres que não queriam ser "recuperadas", "salvas" ou "resgatadas" da prostituição.

Ao mesmo tempo em que eram muito evidentes os enfrentamentos de Gabriela com a instituição "Igreja", ela também mantinha certa proximidade ou admiração em relação a alguns de seus representantes ${ }^{9}$. Essa rede inicial de contatos a aproximou de grupos acadêmicos e intelectuais que já se interessavam por seus discursos e reflexões. Assim como ocorreria em relação a outras redes de pertencimento ao longo de sua trajetória, esses eventos contribuíam para diferenciar ainda mais o seu capital social e cultural em relação a outras prostitutas.

Em 1986, Gabriela estava vinculada ao ISER, no qual fundaria a sua primeira equipe de estudo e assessoria sobre prostituição. Surgido nos anos de 1970, o ISER passou por muitas mudanças, mas no período ao qual nos referimos a ONG tinha como principais atividades a formação, produção de conhecimento e assessorias, trabalho executado por meio de cursos, pesquisas, encontros, palestras e debates. Em sua composição, o ISER contava com a participação de profissionais e acadêmicos de diversas áreas, alguns identificados com estudos sobre religião e sociedade. Caraterizada como uma instituição laica, não deixava também de ser significativo o trânsito de integrantes do ISER reconhecidos como lideranças e intelectuais de diferentes campos religiosos.

Os anos de 1986 e 1987 foram muito significativos na trajetória pública de Gabriela. Esse período possibilitou que ela conhecesse e aprofundasse relações, analogias e tensões com os "outros", questões que marcarão seu ativismo como prostituta. Em 1986, Gabriela participou de um ato público em repúdio ao silêncio que o Vaticano havia imposto ao teólogo Leonardo Boff, no auditório de uma faculdade metodista no Rio de Janeiro ${ }^{10}$. Suas declarações desviaram a atenção, pois Gabriela invadiu aquele espaço público e a cena política para falar sobre a sua experiência como prostituta. Ela foi ovacionada por uma plateia repleta de estudantes, professores, jornalistas, escritores e outros trabalhadores de diferentes segmentos. Inaugurou-se assim um paradigma nos discursos políticos no qual as prostitutas não seriam mais lembradas apenas como grupos-alvo das políticas de controle sanitarista e da repressão policial.

Em 1987, no Rio de Janeiro, Gabriela conduziu a organização do I Encontro Nacional de Prostitutas. 0 evento reuniu ativistas do Rio de Janeiro, Belém, São Paulo, Santos e de outras cidades. 0 acontecimento deu visibilidade à ideia de que as prostitutas haviam se tornado 
uma categoria disposta a reivindicar direitos. Colaboradores, em sua maioria profissionais vinculados a universidades e ONGS, começaram a ganhar a confiança das mulheres participantes do encontro e forneceram uma linguagem política à compreensão da situação das prostitutas e de seus direitos. Laços emocionais, subjetivos, de amizade e confidencialidade, ligaram as prostitutas a esses colaboradores.

Nesse evento, Gabriela lançou o jornal Beijo da rua, um criativo projeto de comunicação que se mostrou duradouro e acompanharia suas passagens por vários círculos sociais e organizações. Editado por Flávio Lenz, jornalista que se tornaria marido e companheiro de trabalho de Gabriela até o fim da vida, o periódico Beijo da rua teve o seu primeiro número lançado em 1988, consagrando-se durante quase três décadas como o principal "porta-voz" do movimento e associações de prostitutas que a partir dali se constituíam.

Uma nova expressão pública das prostitutas emergiu durante esse encontro, por meio da reflexão e do trabalho de autorreconhecimento do grupo. 0 lastro do acontecimento criou notável fronteira na história da prostituição no Brasil. Naquele momento, os noticiários apresentavam as manifestações dessas agentes políticas que reivindicavam o direito à saúde, ao gozo, à livre circulação na cidade, ao exercício da profissão sem vitimizações e preconceitos ${ }^{11}$.

Em 1988, mulheres da Vila Mimosa que estiveram presentes no I Encontro Nacional de Prostitutas criaram no Rio de Janeiro, com o apoio de Gabriela, que já trabalhava no ISER, a primeira associação de prostitutas. No que se refere às mudanças ocorridas nas práticas e nos discursos das instituições, dois eventos destacaram-se nesse período. Um deles mobilizou as prostitutas na defesa da zona de prostituição e contra um pastor de uma igreja protestante que tentava promover a desocupação da área. As mulheres procuraram os meios de comunicação e o episódio terminou por fortalecer em meio à opinião pública a ideia de que elas lutavam por um "direito"12. 0 outro evento foi conhecido pelo nome Piranhódromo, referência a um Projeto de Lei que surgiu no Legislativo Municipal em 1989 cujo objetivo era criar um Centro Integrado de Atendimento ao Meretrício no município do Rio de Janeiro. Gabriela e prostitutas da associação juntaram-se a vereadores e colaboradores para publicizar uma moção de repúdio ao projeto ${ }^{13}$.

No segundo semestre de 1989, o rompimento de Gabriela com a prostituta que presidia a associação da Vila Mimosa tornou-se público. Nesse momento, suas experiências já haviam produzido deslocamentos na percepção que tinha em relação ao seu papel e ação mobilizadores, demonstrando ter outra compreensão de sua posição no movimento social e luta identitária. Esse fato ajuda a compreender a forma como Gabriela vinha aperfeiçoando seu projeto individual, no que diz respeito à sua trajetória pública. Isso não significa que se tratava de um projeto racional, com objetivos e fins últimos previamente definidos. Este foi sendo forjado no processo, no decorrer dos eventos, e com a reflexividade que a ampliação de 
suas participações nos círculos sociais possibilitava. Ao responder às acusações de que teria se afastado da Vila Mimosa e deixado de dar atenção ao local, ilustramos com suas palavras:

Esse discurso da esquerda de quem não pertence às bases não pode representá-la é infundado. Se fosse assim, o Lula (Presidenciável do PT) não poderia ser o candidato do Partido dos Trabalhadores, já que não é mais um torneiro mecânico, e sim um deputado. Quando ela diz isso me magoa, pois nega todo passado meu, de 10 anos de prostituição, que é muito importante para mim. É claro que para levar as nossas reivindicações e a todos os segmentos da sociedade e buscar apoios internacionais, eu preciso viajar, preciso de tempo para isso. E não dá para conciliar as duas coisas. Minha tarefa, no momento, não é exercer diariamente a prostituiçãa, mas lutar pelos direitos das prostitutas a cada minuto — diz Gabriela. (Jornal do Brasil, 13 ago. 1989)

Ao longo desse período, o projeto Prostituição e Direitos Civis, coordenado por Gabriela no ISER, continuava a receber críticas da alta hierarquia católica, especialmente em grupos identificados como mais conservadores ${ }^{14}$. Ao mesmo tempo, entre 1988 e 1994, diferentes encontros regionais reuniram prostitutas adultas e outras categorias de "trabalhadores/as do sexo". O movimento se aproximava, de maneira crescente, de articulações internacionais, criava a sua rede nacional, incorporando temáticas como "Saúde da mulher e prevenção da epidemia pelo HIV". Gabriela participava de encontros de organismos ecumênicos da América Latina e do Caribe e viajava para Nova York, iniciando uma série de palestras em igrejas e organismos de direitos humanos, além de manter contatos com entidades de prostitutas norte-americanas (Folha de São Paulo, 31 jul. 1988).

Ao mesmo tempo em que suas redes sociais e de ativismo político se ampliavam, Gabriela progressivamente revelava sua disposição para agir e pensar com maior autonomia em relação às instituições. Em sua biografia, faz um minucioso relato sobre como ocorreu seu desligamento do ISER, este atribuído, na última fase de um ciclo de conflitos, à crise com um grupo de mulheres acadêmicas e intelectuais da instituição (Leite, 2009: 170-174). Com seu desligamento do ISER, Gabriela criará com Flávio Lenz e com a prostituta Doroth a ONG Davida, na qual permanecerá atuando até seu falecimento. A partir desse acontecimento, serão construídas novas relações que fortalecerão os laços de prostitutas com Gabriela e com essa sua nova organização.

\section{NÃO GOVERNAMENTAL, GOVERNAMENTAL E AS LUTAS CONTRA A AIDS}

a Davida, Gabriela aproxima-se mais de grupos profissionais representantes do Estado
brasileiro e de diferentes ONGs. A Davida participou ativamente da elaboração de 
campanhas e de políticas de prevenção e combate à aids e a outras doenças sexualmente transmissíveis. Nesse percurso, Gabriela vai operar com mais autonomia para realização de projetos e com mais independência na captação de recursos para a realização destes.

A partir dos anos de 1990, as prostitutas emergiram como importantes porta-vozes do Estado e de programas de ação não governamentais. No Brasil, mas também em outras partes do mundo, prostitutas adultas experimentaram diferentes processos políticos nos quais passaram a defender práticas e ideias sobre "sexo seguro" e investiram no reconhecimento da sua condição de agentes de controle do HIV/Aids (Moraes, 2011: 205, 211-214).

Não se pode desconsiderar que, desde o I Encontro Nacional de Prostitutas, no Rio de Janeiro, o tema da aids já estava muito presente entre prostitutas ativistas e na imprensa ${ }^{15}$. A associação criada na Vila Mimosa mantinha convênio com entidades que desenvolviam campanhas para o uso de preservativos. Porém, as políticas desencadeadas naquela época por representantes governamentais e não governamentais não se adiantaram totalmente aos cuidados já tomados por muitas dessas mulheres. Em pesquisa na Vila Mimosa entre os anos 1980-1990, as prostitutas revoltavam-se com o rótulo de "grupo de risco". 0 uso do preservativo era considerado por muitas delas um fator de segurança no trabalho, fazia parte da negociação com o "freguês da zona" e corria entre as mulheres da associação de prostitutas o jargão de que "sexo bom e seguro é sexo feito com mulher pública". O maior problema parecia ser mesmo o acesso ao preservativo, considerado de alto custo, além do comportamento dos homens que, apesar do medo de contraírem a doença, apresentavam muitas resistências à prática do uso (Moraes, 1995: 182-185).

Em parceria com o Ministério da Saúde, o programa coordenado por Gabriela Leite no ISER organizava o primeiro encontro do projeto Previna, de prevenção a aids e a outras doenças sexualmente transmissíveis (Jornal do Brasil, 31 jul. 1987). Posteriormente foram lançados materiais específicos - histórias em quadrinhos com "desenhos explícitos" para travestis e fotonovelas para prostitutas, por exemplo - para grupos classificados, naquele momento, como "de risco". A participação de prostitutas nas metodologias de educação e na multiplicação de informação nas campanhas do governo brasileiro de prevenção à aids, mesmo tendo sido sempre conflitiva, foi importante para o fortalecimento de suas identidades políticas.

No início dos anos 2000, continuavam surgindo e se expandindo movimentos organizados de profissionais do sexo em vários estados brasileiros, que passaram a participar da elaboração e da aplicação de políticas públicas de prevenção a doenças sexualmente transmissíveis e aids ${ }^{16}$. Em grande parte, esses movimentos constituíram-se mediante a criação de associações de prostitutas, com redes e articulações em todo país e com o apoio de ONGs. Abria-se assim um longo caminho de constituição de redes sociais e parcerias entre esses 
diferentes grupos. Antes incluídas nos chamados grupos de risco, as prostitutas passam a ter ativa participação na metodologia de educação ou de multiplicação de informação, atuando como "agentes de saúde". Essas práticas vão também reconstruir as prostitutas adultas como "profissionais do sexo", "trabalhadoras sexuais", "agentes multiplicadores" de práticas de prevenção sexual, enfim, como "mulheres experientes" e capazes de manejar o cuidado de si (Foucault, 1985).

Porém, essas relações, encontros ou parcerias não ocorreram sem tensões ou mesmo rupturas. Foi forte, por exemplo, a reação de prostitutas participantes de campanhas do Ministério da Saúde quando este, em 2013, decidiu censurar materiais com a afirmação "Sou feliz sendo prostituta" - situação que só viria a ser alterada em outro momento (Cesar Lenz, 2014: 44 e 51). Ao analisar a participação de profissionais do sexo da Rede Nacional de Prostituta no combate à epidemia do HIV entre 2011 e 2015, Murray, Kerrigan e Paiva (2018) argumentam que havia por parte dessas mulheres o objetivo de veicular ideias relacionadas com prazer e combate ao estigma. A participação em campanhas, no entanto, foi marcada por censuras, crises políticas e econômicas. Rago (2013: 3.193-3.201) afirma que Gabriela percebia "os dispositivos biopolíticos de controle dos corpos e de higienização da sexualidade", que chegavam com os financiamentos de programas de DST/Aids. Mas a autora refere-se também à habilidade política de Gabriela para as negociações com o Ministério da Saúde, além de conquistas, "legitimando o lugar das prostitutas e a importância do tema da sexualidade no Brasil".

No decorrer desse processo, Gabriela envolveu-se em várias campanhas e planos de enfrentamento à aids, e a sua participação contribuía para institucionalizar o importante papel de ONGs e de prostitutas na criação de políticas nessa área. No período em que o jornal Beijo da rua passou a ser editado pela Davida, em suas páginas reverberaram criticamente as mudanças de cenários, mas desde os anos de 1990 o assunto aids esteve nelas presente. A seção "Coluna da Gabi" mencionava viagens internacionais, parcerias, campanhas, programas com o Ministério da Saúde, com ONGs e de cooperação internacional, com órgãos da Organização das Nações Unidas (ONU), além de contendas com igrejas. No centro dos debates, o importante papel das prostitutas nesse universo:

[...] Vamos encarar de frente um assunto que para nós é muito caro: as políticas de saúde, notadamente as de DST/AIDS. Fomos o primeiro grupo específico no Brasil a apresentar ao Ministério da Saúde um trabalho concreto de prevenção de DST/AIDS entre prostitutas, e no entanto os pretensos técnicos governamentais ou não-governamentais continuam a dar as costas para a história e a nos tratar como os médicos do século passado nos tratavam — objetos de estudo. Este é, para nós, o eixo principal da discussão sobre saúde. (Leite, 1994b: 3) 
No período em que se fortaleciam as políticas antitráfico e de repressão à prostituição, Gabriela e outras prostitutas ativistas também construíram pontes de diálogos e contrapontos indagadores que circularam, diferentemente, entre feministas, representantes dos direitos humanos e grupos profissionais vinculados aos governos. Movimentos de prostitutas brasileiras que não estavam envolvidas com o tráfico sexual reagiram ao rótulo de vitimização que as políticas de combate ao tráfico sexual ressaltavam. 0 trecho citado na sequência retrata a participação de Gabriela em encontros ou conferências internacionais e a sua posição contrária à Coalizão contra o Tráfico de Mulheres (Coalition Against Trafficking in Women - CATW), grupo criado nos anos de 1990 nos Estados Unidos e que se aliou a organizações de direitos das mulheres (Kempadoo, 2016: 2).

[na Ásia] Assisti à cerimônia de abertura num imenso ginásio lotado e à conferência inaugural do secretário-geral da ONU, Kofi Annan. [...] Claro que tudo o que aconteceu na conferência com relação ao trabalho sexual foi muito importante e nós, militantes do movimento de profissionais do sexo de todo o mundo, marcamos um grande gol político na luta pelo nosso protagonismo e pelo nosso lema: "Profissionais do Sexo, Parte da Solução"! [...] cabeças erguidas e orgulhosas, onde o sentimento de estigma e vitimização passa muito longe - mais precisamente em nossos países ocidentais orgulhosos de sua moral sexual repressora e estigmatizante. (Leite, 2004: 12)

Em entrevista com Gabriela, realizada em agosto de 2010, procuramos compreender como a cronologia das fases da vida e as divisões de papéis por idade assumiam importância no contexto das práticas de ação política das prostitutas adultas, ao mesmo tempo definindo identidades e imagens sobre o corpo. Com 59 anos completos, Gabriela afirmou que poderia ser considerada uma "prostituta aposentada", pertencente à "primeira geração de luta contra Aids", papel este com projeção nacional e internacional, que vinha sendo reconhecido pela mídia, por organizações da sociedade civil e do Estado. Mas naquele momento Gabriela ressentia-se também do foco excessivo que prostitutas ativistas agora dirigiam em relação à aids, além da prevalência de uma visão médica na área governamental que dividia "a prostituta da cintura pra baixo".

[...] Eu, apesar de eu ser da primeira geração de luta contra Aids, agora mesmo saí num livro, que o Gapa São Paulo fez [...], sobre cem pessoas que fizeram história da Luta contra Aids no Brasil e eu tô lá, né? Das prostitutas sou eu e a Lourdes Barreto... Eu fui e sou ainda uma lutadora no movimento AIDS, muita coisa pode ser usada pra melhoria de outras práticas do SUS, porque a gente conseguiu coisas inusitadas, quebra de patente, preservativo, um monte de coisa, mas eu tenho um problema com essa questão hoje porque, com a história de muitos projetos do Ministério da Saúde, com a história de existirem esses financiamentos da AIDS, as mulheres começaram a entender que o movimento era só isso. Aí ficou um negócio meio assim... médico, sabe? Ficou aquela história que minha colega da Argentina diz: "se olha a prostituta da cintura pra baixo". (Leite, 2010) 


\section{"PUTAS POLÍTICAS" E A GRIFE DE MODA DASPU}

\section{importância e o orgulho atribuídos ao papel de Gabriela e de outras lideranças nas
lutas contra aids no Brasil não neutralizaram a sua percepção crítica ao desenvol-} vimento de muitas campanhas estatais ou mesmo de outras inciativas com a participação de prostitutas. Suas opiniões foram seguidas por mudanças significativas na trajetória individual, o que mostraremos pelo que chamamos de novo giro performativo. Neste, identifica-se um lastro ainda mais diverso de interlocutores, um reavivamento da sua presença na mídia e uma retomada vigorosa da posição anti-establishment, seja pela via da política ou de uma irreverência em relação ao mercado. Com a equipe da ONG Davida, que fundara, Gabriela criou a grife Daspu e, pouco depois, lançou sua candidatura à Câmara Federal.

A criação da "grife" foi um modelo irreverente de interpelação das formas consagradas de organização do "mercado", ao mesmo tempo em que se tornaria o principal acessório do ativismo político de Gabriela em sua última fase da vida" ${ }^{17}$. Lançada em 2005 "com estampas, frases e design inspirados no mundo da prostituição" e na ideia de "quem não tem vergonha de dizer quem é e o que faz", a "grife" mostrou como o corpo das prostitutas adultas podiam ser socialmente construídos no intuito de valorização e autonomia.

Yaccoub (2009: 2-4) referiu-se à Daspu não como "uma grife para definir padrões e tendências da moda, mas sim abrir por meio da linguagem e (sobretudo) da sexualidade uma brecha para as putas falarem por si mesmas [...]". Flávio Lenz, um dos idealizadores da implantação do projeto, apresentou a grife como "[...] um exemplo de como, na cultura, algumas coisas podem mudar sem política pública. [...] a Daspu é uma forma de desarmar as pessoas, de desmontar com algo inesperado [...] [prostitutas] são sacanas, seduzem, e sem sair do campo da política [...]" (Cesar Lenz, 2017).

Em entrevista que realizamos em 2010, Gabriela ressaltou que com a Daspu o corpo da prostituta deixou de ser visto para o público só como um instrumento de política pública, de prevenção à aids. A Daspu revelou "a coisa lúdica do corpo, e o que é a moda da prostituta". No jornal Beijo da rua, registrou:

[...] Sempre sonhei com a palavra puta sendo falada por todos com a sonoridade e a força que a palavra tem. Sonhos sonhados existem para se tornarem realidade. A Daspu é uma realidade. A Daspu é a moda da puta. [...] 0 caminho está aberto para a puta perder o medo da sociedade e ser com orgulho e prazer a puta cidadã. (Leite, 2005:16)

A Daspu publicizou um corpo de prostituta adulta, que foi sendo normalizado por meio da linguagem da "moda", do lúdico, da autoexpressão, do prazer, da fantasia, do 
gozo, do erótico. Essa construção social divergiu fortemente das imagens do "corpo prostituído" veiculadas pelo senso comum e por muitas instituições. Nestas, os sinais inscritos no corpo das mulheres que vendem serviços sexuais estariam, muito frequentemente, associados ao flagelo e à degradação. A grife também consagrou a política performativa já presente no movimento social de prostitutas e publicizou, de maneira descontraída e irreverente, atributos estigmatizadores da profissão - erotismo, pornografia, nudez etc. A Daspu tornou-se o principal acessório de um ativismo que interpelaria, em outra linguagem, a própria forma do fazer política.

Ao se candidatar a uma vaga na Câmara Federal com o slogan "Puta candidata", Gabriela destacava como bandeira parlamentar o encaminhamento de um Projeto de Lei que tratava do pagamento por serviço de natureza sexual e suprimia artigos do Código Penal (Leite, 2010) ${ }^{18}$. Naquele momento, nosso interesse de pesquisa estava voltado para a questão geracional, e Gabriela expressava que, como assumira muito cedo a identidade de "puta", esta sempre esteve misturada às outras definições identitárias de suas fases de vida, tais como "filha", "mãe" e "avó". Aqui ela destacava outras referências discursivas em torno da mulher prostituta, agora uma identidade afirmada ao mesmo tempo por oposições e sobreposições de papéis de gênero. Para Gabriela, a recorrência ao passado, favorecido pelo processo de produção do seu segundo livro biográfico, permitiu "descobrir" e "aceitar" a sua própria mãe, próxima de completar 80 anos e antes vista como uma mulher severa e de "jeito conservador": "mulher fenomenal [...] que fez da gente [ela e as irmãs] essas mulheres que jamais saem do seu caminho". Palavras e ideias sobre amadurecimento, experiência, sabedoria, liberdade, tranquilidade, felicidade, desejo, permeavam suas descrições sobre os "ganhos" com o avanço do tempo e sugeriam que, nesse contexto específico, ela experimentava outra reflexividade. Com passagens em diversos círculos sociais, Gabriela ressignificava a "puta" construindo outras coerências narrativas que dialogavam com convenções de gênero e sexualidade ${ }^{19}$. Eram diálogos ou mesmo esforços de negociação que se poderiam mostrar instáveis, mas que não deixariam de ser questionadores dos binarismos de gênero. Contextualmente e objetivamente situados, esses diálogos mostravam um autoaperfeiçoamento individual e político, não linear, mas cumulativo.

A imagem da prostituta e do corpo na prostituição adulta é também relacionada às categorias e representações do mundo do trabalho. Nela, inscrevem-se ideias sobre o corpo na ativa e o corpo cansado pelo tempo de atividade, sobre a "prostituta aposentada" e sobre os segredos de um "sucesso profissional". São expressões emblemáticas da vida de outras trabaIhadoras cujos sentidos positivam e normalizam o percurso da mulher adulta na prostituição. 
"Na maior parte da minha vida me senti sexualmente livre [...]. Gozei muito, a vida inteira. Fartamente. A isso se deve grande parte do meu sucesso profissional [...]" (Leite, 2009: 188).

Nesse contexto, em que tentava compreender o seu próprio "amadurecimento político" e no qual ensaiava um balanço da trajetória pessoal e profissional, Gabriela mostrava ser uma personagem pública que observava o passado, mas nunca de forma linear ou normativa. Mesmo desconhecendo aqui a proximidade do que seria o seu período final, ela seguia performatizando as múltiplas possibilidades de manifestação identitária da mulher prostituta.

\section{CONSIDERAÇÕES FINAIS}

o emergir como representante das prostitutas no cenário brasileiro, Gabriela deu visibi-
lidade ao debate sobre prostituição e direitos. A trajetória como ativista do movimento das prostitutas é, em grande parte, representativa dos conflitos entre "controle social", imposto pela sociedade (Elias, 1995: 38-39), e um tipo de agenciamento que, interligado com contextos de mudanças sociais e políticas, empreendeu ações e propagou ideias onde a criatividade pessoa/ se manifestava.

Tornou-se difícil estudar a história recente da prostituição no Brasil sem reconhecer essa nova direção e o papel de Gabriela no emergente processo de mudanças que ocorriam. Nesse sentido, podemos recorrer à expressão "ofensivas civilizatórias" usada por Norbert Elias, como bem lembra Tatiana Landini, para referir-se ao "papel dos grupos organizados no delineamento da direção dos processos sociais" visando influenciar o comportamento social e produzir mudanças, "sejam elas relacionadas à sexualidade e à educação, sejam relacionadas ao Estado" (Landini, 2007: 172).

Gabriela interpelou principalmente modelos deterministas e vitimistas relativos aos papéis de gênero e à dimensão da sexualidade, geralmente acionados para explicar o destino de mulheres na prostituição. Fez isso em vários contextos, ao enfrentar ideias correntes que defendiam a purificação ou o controle das prostitutas como forma de combate ao "sistema imoral" (Piscitelli, 2012: 20-21). À medida que ampliava sua participação em diferentes círculos sociais, Gabriela enfrentava novas tensões e conflitos, mas a circulação de suas ideias também Ihe conferia reconhecimento em muitos embates. Esse percurso Ihe proporcionou experimentar aquilo que na modernidade vem sendo definido como uma sociabilidade plural, aberta, mutante, que cria condições e possibilidades de o indivíduo aumentar a sua expressividade, reconhecendo-se e definindo-se como uma pessoa particular.

Mostramos também que o percurso de Gabriela Leite não é representativo do indivíduo encapsulado, definido por sua excepcionalidade ou personalidade atípica. Foi interagindo, asso- 
ciando-se, acumulando experiência e realizando um trabalho constante de autoaperfeiçoamento em cada círculo social em que penetrava que Gabriela participou e contribuiu com um processo no qual prostitutas passaram a ser vistas como sujeitos políticos. Em contextos sociais específicos, houve, nessa trajetória pessoal, muito esforço de autoconhecimento e de construção de si.

A diferenciação social propiciou também um efeito múltiplo, por vezes paradoxal, perante a expressividade de uma mulher que se afirmava por contrastes com a ordem de gênero e da sexualidade. Ao avocar para si uma identidade dissidente, conhecia a rejeição ou o estigma, ao mesmo tempo em que suas evocações produziam a presença política das prostitutas em várias esferas da vida pública. Nas sinuosas tramas interacionais tecidas nesse percurso, Gabriela rebelava-se e ao mesmo tempo "se estabelecia" e, assim, conhecia as reprovações, as polêmicas, mas também a admiração e o respeito em muitas de suas redes e círculos, tornando-se o que se pode chamar de personalidade pública.

E qual foi a principal contribuição de Gabriela Leite no processo público mais amplo de reconhecimento das prostitutas como sujeitos políticos? Como estavam relacionados a sua trajetória e fenômenos sociais relevantes? São muitos os caminhos e as ramificações pelos quais poderíamos identificar e compreender conexões entre a trajetória de Gabriela com a circulação e a penetração de ideias e valores libertários, democráticos, associados à agenda dos direitos sexuais no Brasil. Porém, em termos de evidência empírica, suas ações e discursos foram centrais para mudanças institucionais, sociais e políticas nas campanhas de prevenção ao HIV/Aids. Tais ações e discursos contribuíram para converter a imagem pública da prostituta como "grupo de risco" à agente de prevenção, informação e esclarecimento. Isso se propagou ao alcançar diferentes redes de atores sociais, e não apenas de representantes de governos, mas também de organizações da sociedade civil que participavam da elaboração dessas políticas. Esse foi um discurso, uma ideia, mas também um valor que penetrou no processo de institucionalização das políticas de prevenção à aids no Brasil. Mesmo tendo ocorrido por meio de limites institucionais frequentemente lembrados por Gabriela e outros atores sociais, 0 sentido público de sua trajetória pessoal também se afirmou nos contornos do duradouro contexto político de combate ao HIV/Aids. Ao mesmo tempo, as redes trançadas em torno dessa trajetória individual desestabilizaram narrativas de desregramento, devassidão, punição, aniquilamento, morte, associadas à questão da aids. A afirmação daquilo que podemos chamar, figurativamente, de uma política da vida por meio do erótico - o que representaria não apenas as práticas discursivas de Gabriela, mas também de muitas prostitutas - propiciou, nesse período, o surgimento de novos contornos no tratamento dessa relevante questão pública. 


\section{NOTAS}

1 Sobre a manifestação de novas identidades coletivas no contexto diverso das lutas pelo reconhecimento de direitos sexuais, consulte também Carrara (2016); Facchini (2005); Vianna e Lacerda (2004).

2 Elias e Scotson (2000: 26) definem as relações entre esses dois grupos: "[...] Eles [outsiders] põem em risco as defesas profundamente arraigadas do grupo estabelecido contra 0 desrespeito às normas e tabus coletivos, de cuja observância depende o status de cada um dos seus semelhantes no grupo estabelecido e seu respeito próprio, seu orgulho e sua identidade como membro do grupo superior".

3 A relação de Mozart com os círculos da corte ("estabelecidos") foi retratada como ambivalente, atração e aversão (Elias, 1995: 38-39). Estendemos essa compreensão aqui para os indivíduos que estão penetrando em novos círculos, o que ganhará mais sentido e consistência nas seções descritivas.

4 Agradeço à Mariana Brasil (minha orientanda no Programa de Pós-Graduação em Sociologia e Antropologia — PPGSA — da Universidade Federal do Rio de Janeiro), por me ter permitido consultar seu arquivo digital do jornal Beijo da rua.

5 Em sua biografia, Gabriela relata uma história familiar marcada por diferentes posições de classe social. Ela conta que seus pais se conheceram na fazenda de café e gado de seus avós paternos, no interior de São Paulo. 0 pai, filho dos donos da fazenda, morava com os avós "num casarão no bairro de Vila Mariana" e nascera "no seio de uma tradicional família quatrocentona". Foi como frequentador de cassinos que seu pai descobrira a profissão de crupiê (Leite, 2009: 11-12). A mãe, "indígena", "[...] ou, como diz a sabedoria popular, [...] cabocla", era filha do capataz da fazenda, que lá vivia com toda a família (Leite, 2009: 11 e 16). Na infância, Gabriela morou no "casarão" da avó paterna, lembrada como uma "matriarca". Com a morte da avó e o dinheiro que coube a seu pai na herança, mudou com a família para um bairro de "periferia de classe média". Ainda no antigo ginásio, resolveu trabalhar para "ter um pouco de liberdade" e "ajudar" a mãe costureira, uma vez que o pai não vivia mais com elas (Leite, 2009: 17 e 20-21).

6 Disponível em: <http://daspu.com.br/gabriela-leite/>. Acesso em: 10 abr. 2020.

7 Personagem do romance Gabriela, cravo e canela, lançado em 1958, associada a atributos como liberdade e sedução, Gabriela foi então o nome escolhido por Otília (Rago, 2013: 2.206). 
8 Disponível em: <http://arquisp.org.br/organizacaopastoral/coordenacao-pastoral-do-servico-da-caridade-justica-e-paz/pastoral-da-mulher-marginalizada>. Acesso em: 19 abr. 2020.

9 Em entrevista ao jornal Mulherio (1987: 3-8): "[...] Dom Mauro [refere-se ao bispo Mauro Morelli] é uma das poucas pessoas da Igreja que ela [Gabriela] diz respeitar: 'um cara mais da vida, mais da rua, não tem jeitão de bispo, dá pra conversar com ele'" .

10 Nome conhecido da "teologia da libertação", o ex-frei franciscano largou o sacerdócio depois que seu livro Igreja: carisma e poder foi censurado em processo movido por uma congregação do Vaticano que o condenou ao silêncio.

11 Conferir Leite (1992) e Moraes (1995: 205-208). Ver também: Jornal do Brasil (21 jul. 1987) e O Globo (21 jul. 1987).

12 Mais informações em Moraes (1995: 224-226). Na imprensa, ver a repercussão em: 0 Globo (23 nov. 1987; 11 dez. 1987); Jornal do Brasil (21 nov. 1987; 26 nov. 1987; 10 dez. 1987; 23 dez. 1987); Tribuna da Imprensa (25 nov. 1987); O Dia (26 nov. 1987; 23 dez. 1987), entre outros.

13 À época, jornais registraram que vereadores haviam recebido uma "caravana de prostitutas", considerada uma "visita inédita" ao legislativo (O Dia, 24 abr. 1989; O Globo, 29 abr. 1989).

140 artigo do bispo D. Marcos Barbosa, publicado no Jornal do Brasil, em 23 de maio de 1991, afirmava: "Existe também uma organização, sem dúvida mais ou menos fantasma, que se encarna de repente em certas iniciativas e cuja sigla, ISER (Instituto Superior de Estudos Religiosos), salvo engano, pode sugerir que a Igreja se integre. 0 que não é possível, quando promovem prostitutas enquanto prostitutas, e não para que tentem mudar de vida".

150 Globo (21 jul. 1987); O Dia (21 jul. 1987); Jornal do Brasil (31 jul. 1987; 19 ago. 1987).

16 Em consulta aos materiais da ONG Davida no Arquivo Público do Estado do Rio de Janeiro (APERJ), identificamos (com Tainá de Oliveira, bolsista da Fundação de Amparo à Pesquisa do Estado do Rio de Janeiro/UFRJ) cinco campanhas e planos de enfrentamento ao HIV/Aids vinculados ao Ministério da Saúde. Com recorte a partir de 2002, essas campanhas e planos ocorreram nos anos de 2002, 2007, 2009, 2012 e 2013.

17 Daspu foi uma referência irônica à Daslu, uma grife multimarca em São Paulo voltada para mulheres da elite do país. No lançamento da Daspu, ainda reverberava o escândalo de sonegação fiscal que envolveu a proprietária da sofisticada loja. Disponível em: <https://exame. abril.com.br/negocios/empresario-baiano-compra-controle-da-rede-de-lojas-daslu/>. Acesso em: 10 abr. 2020. 
18 A campanha referia-se ao projeto, posteriormente arquivado, apresentado pelo então deputado Fernando Gabeira.

19 A reflexividade em uma configuração social específica é contradição e esforço de negociação entre diferentes círculos sociais (Alves e Maciel, 2017: 271- 272).

\section{REFERÊNCIAS BIBLIOGRÁFICAS}

ALVES, A. R. C.; MACIEL, L. C. A individualidade em Simmel e Elias: contribuições teóricas para uma sociologia do indivíduo. Lua Nova, São Paulo, n. 101, p. 259-290, ago. 2017. Disponível em: <http://www.scielo.br/ scielo.php?script=sci_arttext\&pid=S0102-64452017000200259\&/ng=pt\&nrm=iso>. Acesso em: 14 fev. 2020. http://dx.doi.org/10.1590/0102-259290/101.

CARRARA, S. A antropologia e o processo de cidadanização da homossexualidade no Brasil. Cadernos Pagu, Campinas, n. 47, e164717, 2016. Disponível em: <http://www.scielo.br/scielo.php?script=sci_ arttext\&pid=S0104-83332016000200604\&lng=en\&nrm=iso>. Acesso em: 28 fev. 2020. Epub Sep 15, 2016. https://doi.org/10.1590/18094449201600470017.

CESAR LENZ, F. C. O Estado da saúde e a "doença" das prostitutas: uma análise das representações da prostituição nos discursos do SUS e do terceiro setor. In: SIMÕES, S.; SILVA, H.; MORAES, A. F. Prostituição e outras formas de amor. Niterói: Editora da Universidade Federal Fluminense; FAPERJ, 2014. p. 29-56.

Caderno de Entrevistas. [Entrevista via Skype cedida a] Aparecida Fonseca Moraes. Rio de Janeiro/ Alemanha: 18 out. 2017.

ELIAS, N. Mozart: sociologia de um gênio. Rio de Janeiro: Jorge Zahar, 1995.

. O processo civilizador. Rio de Janeiro: Jorge Zahar, 1993. v. 1.

ELIAS, N.; SCOTSON, J. L. Os estabelecidos e os outsiders: sociologia das relações de poder a partir de uma pequena comunidade. Tradução de Vera Ribeiro. Rio de Janeiro: Jorge Zahar, 2000.

FACCHINI, R. Sopa de letrinhas? Movimento homossexual e produção de identidades coletivas nos anos 90. Rio de Janeiro: Garamond, 2005.

FINNEMORE, M.; SIKKING, K. Internacional norm dynamics and political change. International Organization, United Kingdom, v. 52, n. 4, p. 887-917, 1988. https://doi.org/10.1162/002081898550789.

FOUCAULT, M. História da sexualidade. 0 cuidado de si. Rio de Janeiro: Graal, 1985. v. 3.

GALVÃO, J. Aids no Brasil: a agenda de construção de uma epidemia. São Paulo: Editora 34, 2000.

KEMPADO0, K. Revitalizando o imperialismo: campanhas contemporâneas contra o tráfico sexual e escravidão moderna. Cadernos Pagu, Campinas, n. 47, e16478, 2016. Disponível em: <http://www.scielo.br/scielo. php? script=sci_arttext\&pid=S0104-83332016000200405\&lng=en\&nrm=iso>. Acesso em: 14 fev. 2020. http://dx.doi.org/10.1590/18094449201600470008.

LANDINI, T. S. Escritos \& ensaios: Norbert Elias em perspectiva. Revista Brasileira de Ciências Sociais, São Paulo, v. 22, n. 64, p. 169-173, jun. 2007. Disponível em: <http://www.scielo.br/scielo.php?script=sci_ arttext\&pid=S0102-69092007000200015\&lng=pt\&nrm=iso>. Acesso em: 14 fev. 2020. https://doi. org/10.1590/S0102-69092007000200015. 
LEITE, G. Eu, mulher da vida. Rio de Janeiro: Rosa dos Tempos, 1992.

. Filha, mãe, avó e puta: a história de uma mulher que decidiu ser prostituta. Rio de Janeiro: Objetiva, 2009.

2010.. Caderno de Entrevistas. [Entrevista cedida a] Aparecida Fonseca Moraes. Rio de Janeiro: 10 ago.

LEVINE, D. Revisitando Georg Simmel. Sociologia e Antropologia, Rio de Janeiro, v. 5, n. 1, p. 31-52, abr. 2015. Disponível em: <http://www.scielo.br/scielo.php?script=sci_arttext\&pid=S2238-38752015000100031\&lng =en\&nrm=iso >. Acesso em: 10 fev. 2020. http://dx.doi.org/10.1590/2238-38752015v512.

MONTAGNER, M. Â. Trajetórias e biografias: notas para uma análise bourdieusiana. Sociologias, Porto Alegre, n. 17, p. 240-264, jun. 2007. Disponivel em: <http://www.scielo.br/scielo.php?script=sci_arttext\&pid=S151745222007000100010\&lng=en\&nrm=iso>. Acesso em: 8 fev. 2020. http://dx.doi.org/10.1590/S151745222007000100010.

MORAES, A. F. Mulheres da Vila: prostituição, identidade social e movimento associativo. Petrópolis: Vozes, 1995.

. 0 corpo prostituído nas práticas discursivas de organizações dos direitos humanos. In: GOLDENBERG, M. Corpo, envelhecimento e felicidade. Rio de Janeiro: Civilização Brasileira, 2011. p. 199-229.

MURRAY, L. R. M.; KERRIGAN, D.; PAIVA, V. S. Rites of resistance: sex workers' fight to maintain rights and pleasure in the centre of the response to HIV in Brazil. Global Public Health, v. 14, n. 6-7, p. 939-953, Aug. 2018. 10.1080/17441692.2018.1510020.

PHETERSON, G. A vindication of the rights of whores: the international movement for prostitutes rights. Washington: Seal Press, 1989.

PISCITELLI, A. Feminismos y prostitución en Brasil: una lectura a partir de la antropología feminista. Cuadernos de Antropologia Social, Buenos Aires, n. 36, p. 11-31, dez. 2012. Disponível em: <http://www.scielo.org.ar/ scielo.php?script=sci_arttext\&pid=S1850-275X2012000200002\&lng=pt\&nrm=iso>. Acesso em: 14 fev. 2020.

RAGO, L. M. A aventura de contar-se: feminismos, escrita de si e invenções da subjetividade. Campinas: Editora da Unicamp, 2013. https://doi.org/10.7476/9788526814691.

MORAES, E. Formalismo sociológico e a teoria do conflito. In: FILHO, E. M. (org.). Georg Simmel. Sociologia. Tradução de Carlos Alberto Pavanelli. São Paulo: Ática, 1983. p. 7-44.

The intersection of social circles. In: Sociology: inquires into the construction of social forms. Boston: Brill, 2009. p. 36-414.

SKACKAUSKAS, A. 0 benevolente e a "vítima" na prostituição: poder e violência simbólica em interações entre prostitutas e a Pastoral da Mulher Marginalizada. Sexualidad, Salud y Sociologia (Rio de Janeiro), Rio de Janeiro, n. 27, p. 66-96, dez. 2017. Disponivel em: <http://www.scielo.br/scielo.php?script=sci_ arttext\&pid=S1984-64872017000300066>. Acesso em: 28 fev. 2020. https://doi.org/10.1590/1984-6487. sess.2017.27.05.a.

VIANNA, A. R. B.; LACERDA, P. Direitos e políticas sexuais no Brasil: o panorama atual. Rio de Janeiro: CLAM; IMS; CEPESQ, 2004.

YACCOUB, H. Daspu: modos de usar, moda para mudar. In: ENCONTRO ANUAL DA ANPOCS, 33., 2009, Caxumbu. Anais [...]. Caxambu: ANPOCS, 2009. p. 1-22. Disponível em: <https://www.anpocs.com/index. php/papers-33-encontro/gt-28/gt36-4/2172-hilaineyaccou-daspu/file> Acesso em: 7 abr. 2020. 


\section{JORNAIS (POR ORDEM DE APRESENTAÇÃO NO TEXTO)}

LEITE, G. Putas políticas. Beijo da rua, Rio de Janeiro, n. 14, maio 1994a. Coluna da Gabi, p. 2. MULHERIO. São Paulo, p. 3-8, nov. 1987.

LEITE, G. Quem entende a gente? Beijo da rua, Rio de Janeiro, abr. 2002. Coluna da Gabi, p. 16. JORNAL DO BRASIL. A briga das meninas da Vila Mimosa. Rio de Janeiro, 13 ago. 1989. FOLHA DE SÃO PAULO. Prostitutas brasileiras começam a se organizar. São Paulo, 31 jul. 1988. JORNAL DO BRASIL. Prostitutas falam de aids às prostitutas. Rio de Janeiro, 31 jul. 1987.

LEITE, G. III Encontro - "Fazendo história". Beijo da rua, Rio de Janeiro, n. 14, p. 3, 1994b.

LEITE, G. Khobkhunkha, Tailândia. Beijo da rua, Rio de Janeiro, jun./jul. 2004. Coluna da Gabi, p. 12.

LEITE, G. Coluna da Gabi. Beijo da rua, Rio de Janeiro, nov./dez. 2005, p. 16.

JORNAL DO BRASIL. O mangue resiste. Rio de Janeiro, 21 nov. 1987.

O GLOBO. Prostitutas se reúnem sem preconceito. Rio de Janeiro, 21 jul. 1987.

O GLOBO. Prostitutas dizem que pastor quer expulsá-las. Rio de Janeiro, 23 nov. 1987.

O GLOBO. Pastor não quer que a TV Rio tenha prostitutas na vizinhança. Rio de Janeiro, $11 \mathrm{dez}$. 1987.

JORNAL DO BRASIL. Assessor do pastor afirma que versão das prostitutas é irreal. Rio de Janeiro, 26 nov. 1987.

JORNAL DO BRASIL. Ato show pelo Mangue. Rio de Janeiro, 10 dez. 1987.

JORNAL DO BRASIL. Mangue tem seu dia de oração. Rio de Janeiro, 23 dez. 1987.

TRIBUNA DA IMPRENSA. TV de pastor expulsa prostituta do Mangue. Rio de Janeiro, 25 nov. 1987.

O DIA. Prostitutas da Vila Mimosa não fazem ataques ao pastor. Rio de Janeiro, 26 nov. 1987.

O DIA. Prostitutas pedem graças em missa rezada no Mangue. Rio de Janeiro, 23 dez. 1987.

O DIA. Prostitutas vão à Câmara repudiar o piranhódromo. Rio de Janeiro, 24 abr. 1989.

O GLOBO. Confinamento revolta. Rio de Janeiro, 29 abr. 1989.

JORNAL DO BRASIL. Rio de Janeiro, 23 maio 1991.

O DIA. Prostitutas se reúnem no Rio e querem legalização. Rio de Janeiro, 21 jul. 1987.

JORNAL DO BRASIL. Prostitutas falam de Aids às prostitutas. Rio de Janeiro, 31 de jul. 1987.

JORNAL DO BRASIL. No Mangue, resistência à camisinha. Rio de Janeiro, 19 ago. 1987. 


\section{SITES E BLOGS}

http://iserassessoria.org.br/a-instituicao/quem-somos/. Acesso em: 14 mar. 2018.

http://daspu.com.br/gabriela-leite/. Acesso em: 16 nov. 2018.

https://slideplayer.com.br/slide/3670296/. Acesso em: 12 maio 2019.

www.eroticomia.blogspot.com/2007/10/as-passarelas-passeatas-da-daspu.html. Acesso em: 12 maio 2019.

https://exame.abril.com.br/negocios/empresario-baiano-compra-controle-da-rede-de-lojas-daslu/. Acesso em: 10 abr. 2020.

https://filhasdegabriela.wordpress.com/equipe/. Acesso em: 10 abr. 2020.

https://veja.abril.com.br/entretenimento/para-criadora-da-daspu-bruna-surfistinha-fez-literatura-decuriosidades/. Acesso em: 10 abr. 2020.

https://www.bancodaprovidencia.org.br/quemsomos. Acesso em: 10 abr. 2020.

http://arquisp.org.br/organizacaopastoral/coordenacao-pastoral-do-servico-da-caridade-justica-e-paz/ pastoral-da-mulher-marginalizada. Acesso em: 19 abr. 2020. 